\title{
Design a Compact Coplanar Wideband Antenna Used in Radio Frequency Identification Systems
}

\author{
Sufyan Hazaa Ali ${ }^{1}$, Ahmed Hameed Reja ${ }^{2}$, Yousif Azzawi Hachim*3 \\ 1,3 Departement of Electrical Engineering, Tikrit University, Tikrit, Iraq \\ ${ }^{2}$ Department of Electromechanical Engineering, University of Technology, Baghdad, Iraq
}

Correspondence

*Yousif Azzawi Hachim

Tikrit University, Tikrit, Iraq

Email: yousifazzawi@st.tu.edu.iq

\begin{abstract}
In this paper, a new compact coplanar antenna used for Radio frequency identification (FID) applications is presented. This antenna is operated at the resonant frequency of $2.45 \mathrm{GHz}$. The proposed antenna is designed on an epoxy substrate material type (FR-4) with small size of $(40 \times 28) \mathrm{mm}^{2}$ in which the dielectric thickness $(h)$ of $1.6 \mathrm{~mm}$, relative permittivity $\left(\varepsilon_{r}\right)$ of 4.3 and tangent loss of 0.025. In this design the return loss is less than $-10 \mathrm{~dB}$ in the frequency interval $(2.12-2.84) \mathrm{GHz}$ and the minimum value of return loss is $-32 \mathrm{~dB}$ at resonant frequency. The maximum gain of the proposed antenna is $1.22 \mathrm{~dB}$ and the maximum directivity obtained is $2.27 \mathrm{~dB}$. The patch and the ground plane of the proposed antenna are in the same surface. The proposed antenna has a wide bandwidth and omnidirectional radiation pattern with small size. The overall size of the compact antenna is $(40 \times 28 \times 1.635) \mathrm{mm}^{3}$. The Computer Simulation Technology $(C S T)$ microwave studio software is used for simulation and gets layout design.
\end{abstract}

KEYWORDS: Antenna, Gain, Return loss, RFID, Wideband.

\section{INTRODUCTION}

A Radio Frequency Identification (RFID) is rapidly growing technology for automatic identification and it is being exploited in many areas such as healthcare, airport, libraries, military, passport, supply chain etc. [1]. The prodigious development in the field of RFID corresponding uses and applications has increased the requirement of smaller size and low profile elements that appropriate for application in RFID systems. RFID technologies have risen interest to realize several commercial implementations, like security, manufacturing, management of automatic retail, industrial work, access control and transportation, electronic toll collection and distribution systems [2]. A standard RFID system contains a tag and reader devices. The antenna of reader sends an electromagnetic wave (EMW) signal to the tag then RFID reader receives a signal as an information from tag's antenna [3].

The bands of frequency of an RFID are the high frequency (HF) band operates at $13.56 \mathrm{MHz}$, ultra-high frequency (UHF) band from 860 to $960 \mathrm{MHz}$, and Industrial, Scientific, and Medical (ISM) band at 2.4GHz [4],[5]. The applications of an RFID in the ultra-high frequency (UHF) divided to intervals of band of frequencies in many countries. These bands of frequencies are subdivided with respect to countries to: $840.5-844.5 \mathrm{MHz}$ and $920.5-924.5 \mathrm{MHz}$ in China, 902
$928 \mathrm{MHz}$ in North America, 950-956 MHz in Japan, 866$869 \mathrm{MHz}$ in Europe, $865-867 \mathrm{MHz}$ band in India, 920-926 $\mathrm{MHz}$ in Australia, and 908.5-914 MHz in South Korea [6], [7], [8]. The comprehensive coverage of ultra-high frequency (UHF) band used in RFID in each country is about 840-960 MHz. In practical using, the reader antennas usually are circularly polarized $(\mathrm{CP})$ to ensure best communication between tags and reader [9]. A linearly polarized (LP) antenna is necessary for tag antenna, and the RFID tags are mostly oriented arbitrarily [9]. Several limitations are occurs of using distributed patch antennas such as; low gain, narrow bandwidth (NBW) and low efficiency, which leads to reduce the antenna performance [10], [11].

Generally, the basic configuration of conventional microstrip antenna are a conducting patch which is made of metal such gold or copper. The patch is printed on the upper side of the substrate material that has dielectric or relative permittivity value in the range of $2.2 \leqslant \varepsilon \_r \leqslant 12$, which set on the ground layer on the other side as shown in Fig. 1 [12], [13]. The substrate material type FR-4 is used in most designs where the FR-4 dielectric combines good electrical features, price, and availability [14]. 


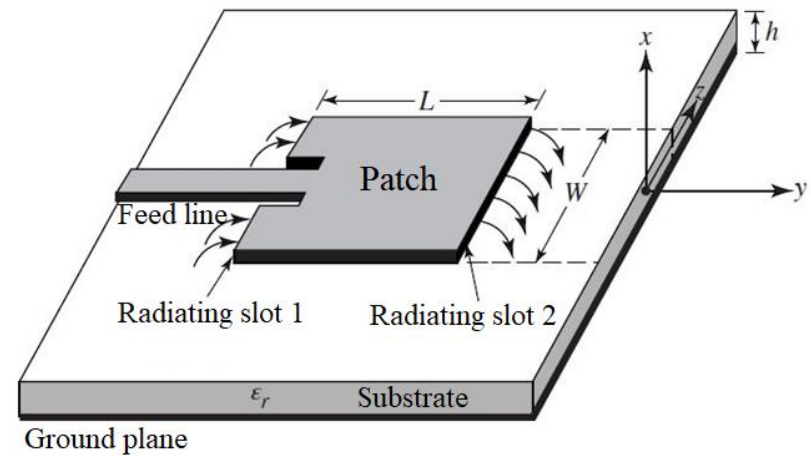

Fig. 1: Microstrip antenna configuration

The main disadvantages of microstrip patch antennas are narrow bandwidth, lesser gain and poor efficiency, which disturbed the efficiency of this antenna. Various researchers currently studied different shapes of antenna design for RFID readers by applying a varied approach of patch and ground geometry [14] . Generally, the miniaturization in size, broad bandwidth and good directivity of RFID antenna systems are important requirements of microstrip antenna and most researches try to develop and modified the antenna specifications.

A. K. Gautam et al. [15] presented a compact antenna made with size of $(30 \times 30 \times 1.6) \mathrm{mm}^{3}$ and narrow bandwidth with acceptable gain value, so the proposed coplanar antenna improved bandwidth. N. O. Parchin et al. [16] presented an antenna to cover dual band of $2.4 / 5.8 \mathrm{GHz}$ RFID operation bands with good realized gain with overall size of $(38 \times 45$ $\times 1.6) \mathrm{mm}^{3}$, so the proposed coplanar antenna improved the size where it has smaller size . M. Z. Aziz et al. [17] presented a dual band omnidirectional antenna to operate at $2.45 \mathrm{GHz}$ in which the dimensions of substrate material are $(15 \times 85.75) \mathrm{mm}^{2}$ and dielectric thickness of $1.6 \mathrm{~mm}$. The return loss at the resonance frequency of $-10.61 \mathrm{~dB}$ with bandwidth is $122 \mathrm{MHz}$ and the gain that has been achieved is $3.798 \mathrm{~dB}$, so the proposed coplanar antenna improved to achieved best return loss. M. R. Reader [18] presented a microstrip stacked patch antenna operates at $2.45 \mathrm{GHz}$ passive RFID reader. The antenna has dimensions of $(58 \times$ 58) $\mathrm{mm}^{2}$ with large thickness of $11 \mathrm{~mm}$ with narrow bandwidth and the peak gain achieves $6.32 \mathrm{~dB}$ in the resonance frequency.

In this work, a microstrip antenna resonated at $2.45 \mathrm{GHz}$ to use in RFID band is designed. This presented antenna is not similar to the traditional microstip antenna, where the patch and the ground are together in same plane (upper surface) as a coplanar technique with omnidirectional radiation. The size of this design is $(40 \times 28 \times 1.635) \mathrm{mm}^{3}$ achieves best impedance matching, acceptable gain, suitable bandwidth and best Voltage Standing Wave Ratio (VSWR). When the value of the VSWR is less than 2 at the frequency band interval, the antenna can be able to work correctly in this band [19].. In detailed structure configuration, design, and simulation results of this design are discussed and explained in the following paragraphs.

\section{ANTENNA DESIGN}

The presented coplanar antenna geometry has partial ground in two separate sections as illustrated in Fig. 2. The presented antenna is printed on substrate material type FR-4 that has thickness $(\mathrm{h})$ of $1.6 \mathrm{~mm}$ and relative permittivity $\left(\varepsilon_{\mathrm{r}}\right)$ of 4.3 and loss tangent $((\tan \delta)$ of 0.025 . The proposed antenna works at the band of frequency in interval $(2.12-$ 2.84) $\mathrm{GHz}$. The dimensions of the general microstrip patch antenna have been obtained [20]. The effective dielectric constant $\left(\varepsilon_{\text {eff }}\right)$ depends on width of the patch antenna $(W)$, dielectric constant $\left(\varepsilon_{\mathrm{r}}\right)$ and the height substrate $(\mathrm{h})$.

The effective dielectric constant ( $\left.\varepsilon_{\text {eff }}\right)$ is calculated as

$\varepsilon_{\text {eff }}=\frac{\varepsilon_{\mathrm{r}}+1}{2}+\frac{\varepsilon_{\mathrm{r}}-1}{2}\left[1+\frac{12 \mathrm{~h}}{\mathrm{~W}}\right]^{-1 / 2}$

The physical dimensions of the microstrip antenna looks smaller than its electrically the patch due to fringing effects. The length of antenna increases due to fringing effect as

$\frac{\Delta \mathrm{L}}{\mathrm{h}}=0.412 \mathrm{~h} \frac{\left(\varepsilon_{\mathrm{eff}}+0.3\right)\left(\frac{\mathrm{W}}{\mathrm{h}}+0.264\right)}{\left(\varepsilon_{\mathrm{eff}}-0.258\right)\left(\frac{\mathrm{W}}{\mathrm{h}}+0.8\right)}$

$\Delta L$ is the extension patch length due to fringing

The effective length is calculated by

$L_{\text {eff }}=\frac{1}{2 f_{o} \sqrt{\varepsilon_{\text {reff }}} \sqrt{\mu_{o} \varepsilon_{o}}}=\frac{v_{o}}{2 f_{o} \sqrt{\varepsilon_{\text {reff }}}}$

The width of patch antenna is calculated by

$\mathrm{W}=\frac{1}{2 \mathrm{f}_{\mathrm{o}} \sqrt{\mu_{\mathrm{o}} \varepsilon_{\mathrm{o}}}} \sqrt{\frac{2}{\varepsilon_{\mathrm{r}}+1}}=\frac{\mathrm{v}_{\mathrm{o}}}{2 \mathrm{f}_{\mathrm{o}}} \sqrt{\frac{2}{\varepsilon_{\mathrm{r}}+1}}$

$\mathrm{v}_{\mathrm{O}}$ is speed of light in free space

$\mathrm{f}_{\mathrm{o}}$ is resonance frequency

Where $\mathrm{v}_{\mathrm{o}}=3 \times 10^{8} \mathrm{~m} / \mathrm{s}, \mu_{\mathrm{o}}=4 \pi \times 10^{-7} \mathrm{H} / \mathrm{m}$ and

$\varepsilon_{\mathrm{o}}=8.85 \times 10^{-12} \mathrm{~F} / \mathrm{m}$

The actual length $\left(\mathrm{L}_{\mathrm{act}}\right.$. $)$ of the patch is calculated by

$\mathrm{L}_{\text {act. }}=\mathrm{L}_{\mathrm{eff}}-2 \Delta \mathrm{L}$

The dimensions of the substrate as Length $\left(\mathrm{L}_{\text {substrate }}\right)$ and

Width $\left(\mathrm{W}_{\text {substrate }}\right)$ are specified as

$\mathrm{W}_{\text {substrate }}=\mathrm{W}+6 \mathrm{~h}$

$\mathrm{L}_{\text {substrate }}=\mathrm{L}+6 \mathrm{~h}$

By using the above equations, the dimensions of antenna are achieved as shown in Fig. 2. 


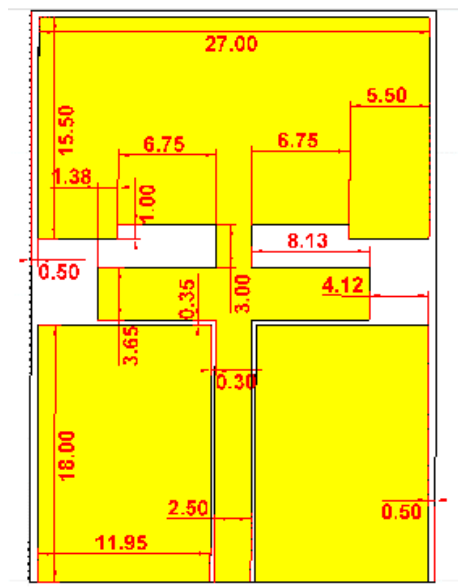

Fig. 2: Geometry of the proposed antenna

From this design we conclude that to achieved the resonant frequency demanded with suitable size we must add the slots, also to achieve good impedance matching, best return loss, wide bandwidth and minimum VSWR. To achieved omnidirectional radiation pattern, the ground must be partial ground.

The materials of this antenna and its dimensions and thicknesses are registered in Table I.

\section{TABLE I DIMENTIONS OF THE PROPOSED ANTENNA}

\begin{tabular}{|l|c|c|c|}
\hline Elements & $\begin{array}{c}\text { Material } \\
\text { type }\end{array}$ & $\begin{array}{c}\text { Dimensions in } \\
\mathrm{mm}^{2}\end{array}$ & $\begin{array}{c}\text { Thickness } \\
\text { in mm }\end{array}$ \\
\hline Substrate & FR-4 & $40 \times 28$ & 1.6 \\
\hline ground element & Copper & $18 \times 11.95$ & Too low \\
\hline Patch & Copper & $21.65 \times 27$ & Too low \\
\hline Feed line & Copper & $18.35 \times 2.5$ & Too low \\
\hline
\end{tabular}

\section{SIMULATION RESULTS AND DISSCUISIONS}

At first, the return loss (RL) or reflection coefficient $|\mathrm{S} 11|$ is calculated as a function of frequency and illustrated in Fig. 3 . The simulated bandwidth evaluated at $-10 \mathrm{~dB}$ is $720 \mathrm{MHz}$ that is measured in the frequency range $(2.12-2.84) \mathrm{GHz}$. Thereafter, the other important parameter with return loss, that effects on antenna performance and related to the bandwidth, is Voltage Standing Wave Ratio (VSWR), and it is less than or equal to 2 . (VSWR $\leq 2$ ).

The VSWR response of the proposed antenna is illustrated in Fig. 4. As can be showed in Fig. 4, the deepest or less value of VSWR is 1.05 occurs at the resonance frequency of 2.45 $\mathrm{GHz}$ that means the maximum power will be transferred at the operated frequency $(2.45 \mathrm{GHz})$.

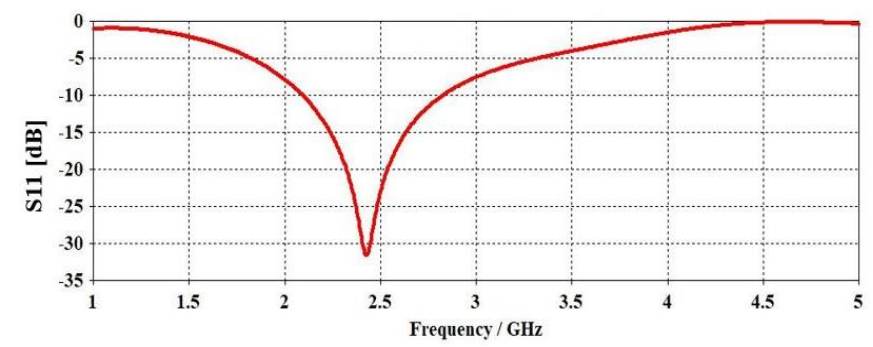

Fig. 3: Return loss verses frequency

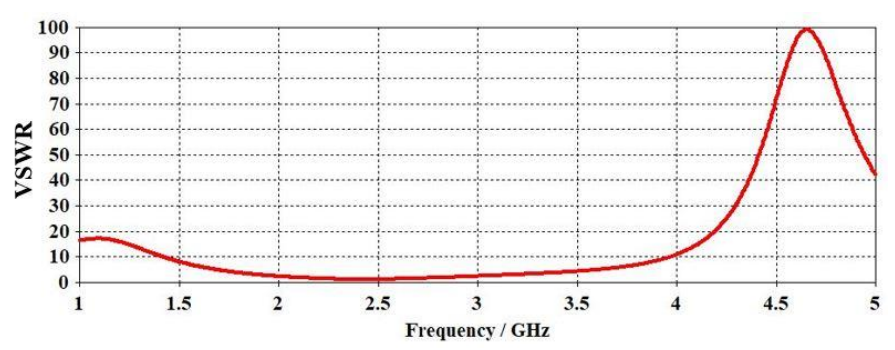

Fig. 4: The VSWR of the proposed antenna

As observed from the appreciated gain curve of the presented antenna design in Fig. 5, a suitable amount gain of $1.22 \mathrm{~dB}$ is obtained.

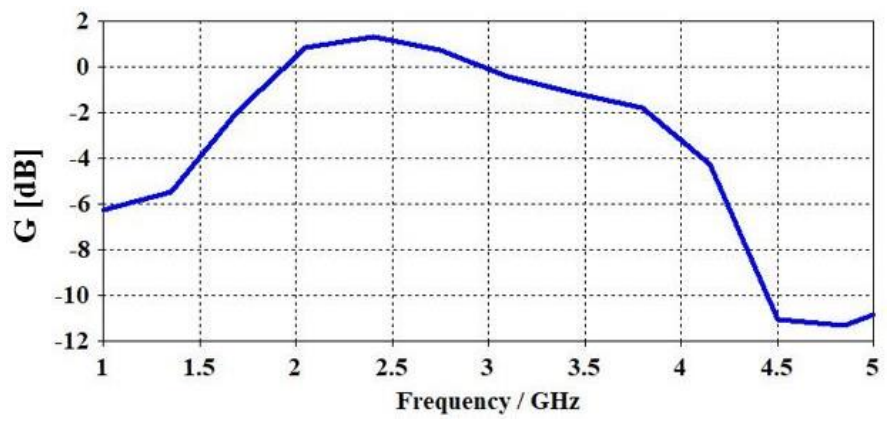

Fig. 5: The response gain of the proposed antenna

The other considerable parameter related to the gain $(\mathrm{G})$ that interested in antenna performance is the directivity (D). Fig. 6 shows the directivity of radiation pattern of the presented antenna. Theoretically, the relation between the gain $(\mathrm{G})$ and directivity (D) is related to antenna efficiency factor $(\eta)$ as in (8).

$G=\eta D$

The antenna efficiency factor value is enclosed by $(0 \leq \eta \leq$ 1). If $\eta=1$, that means the antenna is lossless. In practice, gain $(\mathrm{G})$ is always less than the directivity (D). As showed in the Fig. 6, the omnidirectional radiation pattern is obtained. Thus the maximum value of directivity resulted is $2.27 \mathrm{~dB}$. 


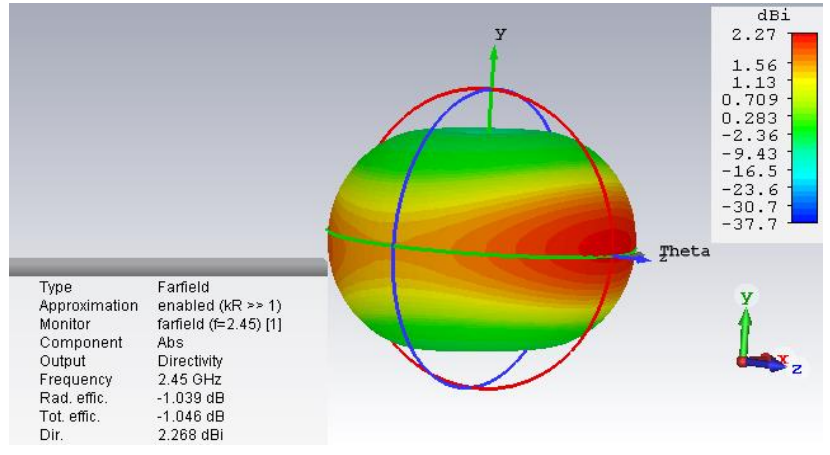

Fig. 6: Radiation pattern with all defined parameters

The brief of simulated results for the offered antenna is listed in Table II.

TABLE II

SUMMARY RESULTS OF SIMULATED PARAMETERS

\begin{tabular}{|l|l|}
\hline Antenna parameters & Value \\
\hline Frequency range & $2.12-2.84 \mathrm{GHz}$ \\
\hline Resonance frequency $\left(f_{\mathrm{o}}\right)$ & $2.45 \mathrm{GHz}$ \\
\hline Bandwidth & $720 \mathrm{MHz}$ \\
\hline Return Loss at $f_{\mathrm{o}}$ & $-32 \mathrm{~dB}$ \\
\hline VSWR at $f_{\mathrm{o}}$ & $1.05 \mathrm{~dB}$ \\
\hline Directivity & $2.27 \mathrm{~dB}$ \\
\hline Gain & $1.22 \mathrm{~dB}$ \\
\hline
\end{tabular}

\section{CONCLUSION}

This work presented a wideband microstrip slots loaded patch antenna as a coplanar with microstrip feed line. By using partial ground method (i.e. this theory used to obtain omnidirectional radiation pattern) the antenna performance has been improved where the parameter results of the suggested antenna present less return loss, broad bandwidth, minimum VSWR and proper directivity with reasonable value of gain furthermore miniaturization in antenna size. The suggested antenna has small size and operates in the frequency band of $(2.12-2.84) \mathrm{GHz}$ which represent the suitable band to cover RFID applications at resonant frequency of $2.45 \mathrm{GHz}$, the gain and directivity values are $1.22 \mathrm{~dB}$ and $2.27 \mathrm{~dB}$ respectively.

\section{CONFLICT OF INTEREST}

The authors have no conflict of relevant interest to this article.

\section{REFERENCES}

[1] F. Xavier, O. K. Hikage, M. S. de Paula Pessôa, and A. L. Fleury, "A View about RFID Technology in Brazil," in PICMET 2010 Technology Management for Global Economic Growth, 2010, pp. 1-9.

[2] K. Finkenzeller, RFID handbook: fundamentals and applications in contactless smart cards, radio frequency identification and near-field communication, $3^{\text {rd }}$ ed., John wiley \& sons, Munich, Germany, 2010.

[3] W.-S. Chen and Y.-C. Huang, "A Novel CP Antenna for UHF RFID Handheld Reader," IEEE Antennas Propag. Mag., vol. 55, no. 4, pp. 128-137, 2013.

[4] J.-H. Lim, B.-S. Kang, J.-W. Jwa, H.-S. Kim, and D.-Y. Yang, "RFID Reader Antenna with Hilbert Curve Fractal Structure over Partially Grounded Plane," J. Korea Contents Assoc., vol. 7, no. 4, pp. 30-38, 2007.

[5] Y. Jin, J. Tak, and J. Choi, "Quadruple Band-notched Trapezoid UWB Antenna with Reduced Gains in Notch Bands," J. Electromagn. Eng. Sci., vol. 16, no. 1, pp. 3543, 2016.

[6] Z. N. Chen and X. Qing, "Asymmetric-circular Shaped Slotted Microstrip Antennas for Circular Polarization and RFID Applications," IEEE Trans. Antennas Propag., vol. 58, no. 12, pp. 3821-3828, 2010.

[7] R. Cao and S.-C. Yu, "Wideband Compact CPW-fed Circularly Polarized Antenna for Universal UHF RFID Reader," IEEE Trans. Antennas Propag., vol. 63, no. 9, pp. 4148-4151, 2015.

[8] J. H. Yoon, S. J. Ha, and Y. C. Rhee, "A Novel Monopole Antenna with Two Arc-shaped Strips for WLAN/WiMAX Application," J. Electromagn. Eng. Sci., vol. 15, no. 1, pp. 6-13, 2015.

[9] X.-Z. Lai, Z.-M. Xie, Q.-Q. Xie, and X.-L. Cen, "A Dual Circularly Polarized RFID Reader Antenna with Wideband Isolation," IEEE Antennas Wirel. Propag. Lett., vol. 12, pp. 1630-1633, 2013.

[10] G. Kaur, G. Singla, and S. Kaur, "Design of Wideband Micro strip Patch Antenna Using Defected Ground Structure for Wireless Applications," Int. J. Adv. Res. Comput. Sci. Softw. Eng., vol. 3, no. 10, 2013.

[11] J. M. Patel, S. K. Patel, and F. N. Thakkar, "Comparative Analysis of S-shaped Multiband Microstrip Patch Antenna," Int. J. Adv. Res. Electr. Electron. Instrum. Eng., vol. 2, no. 7, pp. 3273-3280, 2013.

[12] B. S. Sandeep and S. S. Kashyap, "Design and Simulation of Microstrip Patch Array Antenna for Wireless Communications at $2.4 \mathrm{GHz}$," Int. J. Sci. Eng. Res., vol. 3, no. 11, pp. 1-5, 2012.

[13] S. A. Ali, U. Rafique, U. Ahmad, and M. A. Khan, "Multiband Microstrip Patch Antenna for Microwave Applications," IOSR J. Electron. Commun. Eng., vol. 3, no. 5, pp. 43-48, 2012.

[14] D. G. Fang, Antenna Theory and Microstrip Antenna, United States of America: Taylor and Francis Group, LLC, 2010.

[15] A. K. Gautam, N. Agrawal, and K. Rambabu, "Design and Packaging of a Compact Circularly Polarised Planar Antenna for 2 . 45-GHz RFID Mobile Readers," vol. 13, pp. 2310-2314, 2019.

[16] N. O. Parchin, H. J. Basherlou, R. A. Abd-Alhameed, and J. M. Noras, "Dual-band Monopole Antenna for RFID Applications," Futur. Internet, vol. 11, no. 2, 2019.

[17] M.Z.A. A. Aziz, M. Md. Shukor, M.K. Suaidi, B.H. Ahmead, M.F. Johar, H. Nornikman, F.A. Azmin, S.N. Salleh and M.F. Abd. Malek, "Printed Omnidirectional Antenna for RFID Applications," 2013 IEEE Int. Conf. RFID-Technologies Appl. RFID-TA 2013, pp. 4-5, 2013. 
[18] M. R. Reader, "A Compact and Broadband Microstrip Stacked Patch Antenna With Circular Polarization for 2.45-GHz Mobile RFID Reader," IEEE Antennas and Wireless Propagation Letters, vol. 12, pp. 623-626, 2013.

[19] B. Niboriya, C. Choudhary, and G. Prabhakar, "S-shape Wideband Microstrip Patch Antenna with Enhanced Gain and Bandwidth for Wireless Communication," Int. J. Comput. Appl., vol. 73, no. 7, pp. 975-8887, 2013.

[20] C. A. Balanis, Antenna Theory Analysis and Design, 4th ed. United States of America: John Wiley Sons, 2016. 